\title{
PRODUÇÃO SOBRE ASSÉDIO SEXUAL NO PERÍODO DE 2010 A 2019: UM ESTUDO
}

\author{
BIBLIOMÉTRICO
}

\author{
Gisela Sartori Farencena ${ }^{1}$ \\ https://orcid.org/0000-0002-5927-3199 \\ Sheila Kocourek ${ }^{2}$ \\ http://orcid.org/0000-0001-8962-8758 \\ Andreia Moro da Silva \\ https://orcid.org/0000-0002-0409-3625 \\ Eric Charles Henri Dorion ${ }^{4}$ \\ https://orcid.org/0000-0002-3472-3835 \\ Recebido em: 9 nov. 2020 \\ Aceito em: 9 dez. 2020
}

Como citar este artigo: SARTORI FARENCENA, G.; KOCOUREK, S.; MORO DA SILVA, A.; HENRI DORION, E. C. PRODUÇÃO SOBRE ASSÉDIO SEXUAL NO PERÍODO DE 2010 A 2019: UM ESTUDO BIBLIOMÉTRICO. Revista Visão: Gestão Organizacional, Caçador (SC), Brasil, v. 9, n. 2, p. 122-137, 2020. DOI: https://doi.org/10.33362/visao.v9i2.2415. Disponível em: https://periodicos.uniarp.edu.br/index.php/visao/article/view/2415.

Resumo: O assédio sexual é uma forma de violência que atinge, diariamente, muitas mulheres. Como uma prática recorrente, espera-se que a temática também venha recebendo atenção por parte dos pesquisadores. Assim, este estudo tem como objetivo analisar a produção científica sobre o assédio sexual entre os anos de 2010 e 2019, mais especificamente no que se refere à Administração e áreas afins. Para isso, foi realizado um estudo bibliométrico em duas bases de dados: da ANPAD (Associação Nacional de Pós-Graduação e Pesquisa em Administração), fazendo uma breve análise dos trabalhos encontrados; e Web of Science, onde foram analisados o perfil geral das publicações (principais áreas que pesquisam o tema, ano, autores, idiomas e países) e as características dos dez artigos mais citados na referida base. A partir dos artigos encontrados nas bases, foi possível perceber que o assédio sexual no local de trabalho foi uma forte tendência de pesquisa no período analisado, mas há carência de estudos dessa forma de assédio em organizações públicas.

Palavras-Chave: Assédio sexual. Produção científica. Bibliométrico.

\footnotetext{
1 Mestre em Gestão de Organizações Públicas. Universidade Federal de Santa Maria (UFSM). E-mail: gisela.adm.95@gmail.com.

${ }^{2}$ Doutora em Serviço Social. Universidade Federal de Santa Maria (UFSM). E-mail: sheilakocourek@gmail.com.

3 Pós-Graduada em Saúde Coletiva. Universidade Federal de Santa Maria (UFSM). E-mail: andreiammoro@gmail.com.

4 Doutor em Administração de Empresas. Universidade Federal de Santa Maria (UFSM). E-mail: echdorion@gmail.com.
} 
PRODUCTION ABOUT SEXUAL HARASSMENT FROM 2010 TO 2019: A BIBLIOMETRIC STUDY

Abstract: Sexual harassment is a form of violence that daily affects many women. As a recurring practice, it is expected that the theme will also receive attention from researchers. Thus, this study aims to analyze the scientific production on sexual harassment between the years 2010 and 2019, more specifically with regard to Administration and related areas. For this, a bibliometric study was carried out in two databases: from ANPAD (National Association of Graduate Studies and Research in Administration), making a brief analysis of the works found; and Web of Science, where the general profile of the publications (main areas that research the theme, year, authors, languages and countries) and the characteristics of the ten most cited articles in that database were analyzed. From the articles found in the databases, it was possible to perceive that sexual harassment in the workplace was a strong research trend in the analyzed period, but there is a lack of studies on this form of harassment in public organizations.

Keywords: Sexual harassment. Scientific production. Bibliometric.

\section{INTRODUÇÃO}

Todos os dias, muitas pessoas, sobretudo mulheres, são vítimas de diferentes tipos de violência e discriminação. Um desses tipos de violência e também consequência da discriminação de gênero é o assédio sexual, que ocorre devido às raízes presentes em nossa sociedade. As mulheres viveram e ainda vivem questões de desigualdade em relação aos homens em diversas esferas de suas vidas. Vivem em uma sociedade machista, onde a mulher é considerada o sexo frágil, e patriarcal, onde o homem é percebido como autoridade dentro de casa, recebe salários maiores, ocupa posições melhores dentro das empresas.

Tem-se o estereótipo formado sobre o homem, que é visto como "indivíduo corajoso, viril, esperto, forte e imune às fragilidades" (OSTERNE, 2012, p. 130), o que parece que lhes dá o direito de agir de modo agressivo contra as mulheres, especialmente porque estas, ainda de acordo com a mesma autora, têm o estereótipo baseado na fraqueza e na fragilidade. Tudo isso colabora para que a mulher seja desvalorizada perante os homens, o que acaba ocasionando violências como o assédio sexual.

O assédio sexual está relacionado com a insistência inoportuna em obter algum favorecimento sexual. Envolve duas partes, o assediador, sujeito que pratica o assédio, e o assediado, que o sofre. Essa forma de assédio pode facilmente ser confundida com paquera. Sabe-se que existe uma linha tênue entre brincadeiras, flerte e assédio sexual, o que acaba deixando dúvida, muitas vezes, para a vítima, sobre a ocorrência ou não do assédio. Isso muitas vezes colabora para que não haja a denúncia, visto que não há certeza sobre a ocorrência do assédio sexual. Nesse sentido, é importante observar definições que possam trazer elucidações. "Elogios sem conteúdo sexual, cantadas, paqueras ou flertes consentidos não 
constituem assédio sexual. Para caracterizar o assédio sexual, é necessário o "não consentimento" da pessoa assediada e o objetivo, por parte de quem assedia, de obter vantagem sexual" (SENADO FEDERAL, 2011, p. 18).

Apesar de prática muito recorrente na realidade, alguns autores acreditam que o tema não vem sendo muito trabalhado no meio acadêmico. Para Santos (2018), a falta de estudos sobre assédio sexual no Brasil pode se dar devido ao fato de que o país é fortemente marcado pela cultura machista e patrimonialista. Diniz (2014, p. 224) também comenta sobre a baixa quantidade de estudos na área e coloca que "é possível aventar a hipótese de que a não inclusão de modalidades de violência (principalmente do assédio sexual) nas discussões acadêmicas, reflete a forma como, em geral, a sociedade também os trata". Ou seja, na prática, a sociedade acaba fechando os olhos para esses problemas, por se tratarem de assuntos polêmicos e delicados.

Diante disso, o objetivo deste estudo é analisar a produção científica sobre assédio sexual entre os anos de 2010 e 2019, na área da Administração ou áreas afins, a partir das bases de dados da ANPAD, que reúne os mais importantes estudos brasileiros na área da Administração, e Web of Science, que engloba importantes estudos internacionais. Por meio deste levantamento, espera-se conhecer o panorama de produções e contribuir par a os avanços de pesquisas sobre o tema.

Este artigo está estruturado da seguinte maneira: introdução, fundamentação teórica, procedimentos metodológicos, resultados e considerações finais.

\section{FUNDAMENTAÇÃO TEÓRICA}

O assédio sexual é uma forma de violência que tem suas raízes no patriarcalismo e no machismo, características muito presentes na sociedade desde os primórdios. O patriarcalismo é "caracterizado por uma economia domesticamente organizada, na qual as mulheres tornamse objeto de satisfação sexual dos homens, reprodutoras de herdeiros, de trabalho e de novas reprodutoras" (OSTERNE, 2012, p. 131). O machismo refere-se à naturalização da superioridade dos homens perante as mulheres. Diante desses aspectos, o homem se sente no direito de se fazer superior à mulher, de ameaçá-la, agir com violência. A mulher, muitas vezes por medo, acaba por se calar e aceitar a situação que foi naturalizada pela sociedade. Todavia, muitas não se calam. Lutaram, durante toda história, e ainda lutam por seus direitos, em busca do fim de toda desvalorização.

Desde 2001, o assédio sexual passou a ser considerado crime no Brasil. O Código Penal Brasileiro, em seu artigo 216-A, define o assédio sexual como ato de "constranger alguém com o intuito de obter vantagem ou favorecimento sexual, prevalecendo-se o agente da sua condição de superior hierárquico ou ascendência inerentes ao exercício de emprego, cargo ou 
função". Prevê como pena para o agressor detenção de 1 a 2 anos, que pode ser aumentada em até um terço se a vítima for menor de idade. Teixeira e Rampazo (2017, p. 1160) citam que tal hierarquia pode se referir tanto a uma relação de poder institucionalizada e formalizada como relação de orientação ou outro nível de subordinação - quanto em outras relações que não envolvam necessariamente hierarquia explícita, mas que recorram a uma hierarquização de gênero socialmente construída.

Apesar de tardia, a criminalização do assédio sexual foi um avanço muito importante para a sociedade, visto que estamos inseridos em um ambiente onde a pessoa que pratica o assédio sexual é tolerada, pois sua atitude é amenizada quando confundida com brincadeira de mau gosto ou até chamada de cantada infeliz (SANTOS, 2018). Como já mencionado, isso se dá especialmente pelo fato de vivermos uma cultura muito machista e ainda patriarcal, que acaba amenizando este tipo de atitude.

Mas, embora já seja considerado crime, muitas pessoas seguem sendo vítimas dessa forma de violência que, por muitas vezes, passa despercebida ou é ignorada por diferentes razões, que podem envolver o medo de denunciar o agressor, o medo de retaliação, de perder o emprego, de não acreditarem na sua versão, entre outros. Enfim, se torna difícil enfrentar as relações de poder existentes e o julgamento por parte da sociedade, essa que, por vezes, interpreta o assédio sexual como parte da arte da conquista (TEIXEIRA; RAMPAZO, 2017).

Ao contrário do que se pode imaginar, para que seja configurado o assédio sexual, não é necessário que haja contato físico do assediador com relação ao assediado, uma vez que, de acordo com o Conselho Nacional do Ministério Público [CNMP] (2016, p. 18), "essa prática pode ser clara, como expressões verbais ou escritas, ou de formas mais sutis, como comentários, gestos, imagens enviadas por e-mail", entre outros. Tendo em vista a necessidade do entendimento sobre o assédio sexual, o Senado Federal produziu uma cartilha, chamada Cartilha sobre Assédio Moral e Sexual, organizada pelo Programa Pró-Equidade de Gênero e Raça. Esta aponta alguns exemplos de situações que caracterizam assédio sexual, a saber: contato físico indesejado, convites impertinentes, promessas de tratamento diferenciado, chantagem para permanência ou promoção no emprego, conversas indesejáveis sobre sexo, exibicionismo, solicitação de favores sexuais, entre outras situações.

Por ser um problema tão grave, obviamente o assédio sexual traz consequências negativas para a vítima, dentre elas: "irritabilidade, ansiedade, tensão, depressão, deterioração das relações pessoais, hostilidade, insônia, fadiga e outros sintomas de estresse no trabalho" (OLETO et al., 2018, p. 46); "sentimento de culpa, pensamentos suicidas, uso de álcool e drogas, cansaço, falta de interesse pelo trabalho, isolamento, diminuição da capacidade de concentração, sensação negativa em relação ao futuro, entre outras" (CNMP, 2016, p. 22). Tudo isso pode ser ainda mais agravado quando a vítima convive com este problema em silêncio, o que pode gerar uma sobrecarga ainda maior. 
Além de todas as más consequências citadas, sofrer assédio sexual acarreta uma grande humilhação para a vítima. Quando no ambiente de trabalho, o assédio pode ser ainda mais constrangedor e humilhante, visto que é um local que a vítima frequenta diariamente, e pode ter que conviver com o assediador com grande frequência. Mas, ao contrário do que muitos imaginam, nem sempre o assédio sexual no ambiente de trabalho vem por parte do chefe hierárquico. Para Teixeira e Rampazo (2017, p. 1173), "pode também ocorrer entre pares, e de um subordinado para seu superior". Independentemente de quem seja o assediador, o assédio no local de trabalho traz graves consequências psicossociais, além de afetar a produtividade no trabalho, podendo afetar o sujeito de forma irreversível (OLETO; PALHARES, 2019).

O assédio sexual pode estar intimamente ligado ao assédio moral, principalmente quando se trata do ambiente de trabalho, onde o superior acaba usando de seu poder para convencer o subordinado a prestar favores sexuais para que não seja prejudicado no trabalho, ou até mesmo demitido (OLETO et al., 2018), situação que acaba configurando a ocorrência das duas formas de assédio. Mas, ainda assim, as duas formas de assédio não devem ser confundidas. Enquanto o assédio sexual caracteriza-se pela dominação da vítima sexualmente em função do poder que perpassa relações desiguais de gênero, o assédio moral visa a eliminação dos sujeitos do mundo do trabalho adotando medidas de abuso de poder, através de humilhação, manipulação, não tendo necessariamente o recorte de gênero (DINIZ, 2014), sendo esta uma das grandes diferenças entre eles.

Diante da gravidade da temática, a seguir, serão detalhados os procedimentos metodológicos adotados neste estudo, que busca analisar as produções referentes ao tema.

\section{MATERIAL E MÉTODOS}

Esta pesquisa tem por objetivo realizar um levantamento quanto à produção científica sobre assédio sexual nos últimos 10 anos (2010-2019). Assim, caracteriza-se como uma pesquisa descritiva, de caráter quantitativo e qualitativo. Para atingir o objetivo, foi realizado um levantamento bibliométrico que, de acordo com Araújo (2006, p. 12), é uma "técnica quantitativa e estatística de medição dos índices de produção e disseminação do conhecimento científico".

As principais leis da bibliometria são a Lei de Lotka, Lei de Bradford e Lei de Zipf. A Lei de Lotka baseia-se no princípio de que grande parte da produção científica é produzida por poucos autores. A Lei de Bradford trabalha com a ideia de que poucos periódicos produzem muitos artigos. A Lei de Zipf está relacionada à ocorrência de palavras em um texto (JUNIOR et al., 2016), e foi nesta última lei que este artigo se baseou, uma vez que foram buscados artigos a partir de palavras específicas nas bases. 
A pesquisa dividiu-se em etapas. Primeiramente foi buscada a produção sobre o tema a partir da base de dados da ANPAD ${ }^{5}$, no dia 24 de janeiro de 2020. Na sequência, procedeu-se à análise da produção na base Web of Science, com busca realizada em 27 de janeiro de 2020. Na base da ANPAD, realizou-se a busca através do descritor "assédio sexual", sem utilização de filtros e refinamentos. A partir do resultado encontrado, foram analisados os autores, universidades às quais pertencem e ano de publicação. Ademais, foi feita uma breve análise sobre o conteúdo das pesquisas encontradas. Na Web of Science foi realizada a busca pelo descritor "sexual harassment" no título dos documentos, utilizando o refinador de busca quanto ao intervalo de tempo de 2010 a 2019. Além disso, também foi feito refinamento por tipo de documento, selecionando apenas artigos. Assim, foram levantadas as seguintes informações: número total de publicações e áreas temáticas.

Posteriormente, foi realizado um refinamento da pesquisa, buscando produções da área de administração ou relacionadas, utilizando o filtro, a critério dos autores, a partir das seguintes áreas: Public Administration; Business; Management; Social Science Interdiciplinary; Social Work. Com isso, o número de documentos foi reduzido de 507 para 83. A partir deste número, foram levantadas novas informações: autores em destaque, ano das publicações, idiomas e países. Na sequência, foi feita uma breve análise dos dez artigos mais citados na base de dados. A Figura 1 apresenta o desenho do processo de busca na Web of Science.

Figura 1 - Desenho do processo de busca na Web of Science.

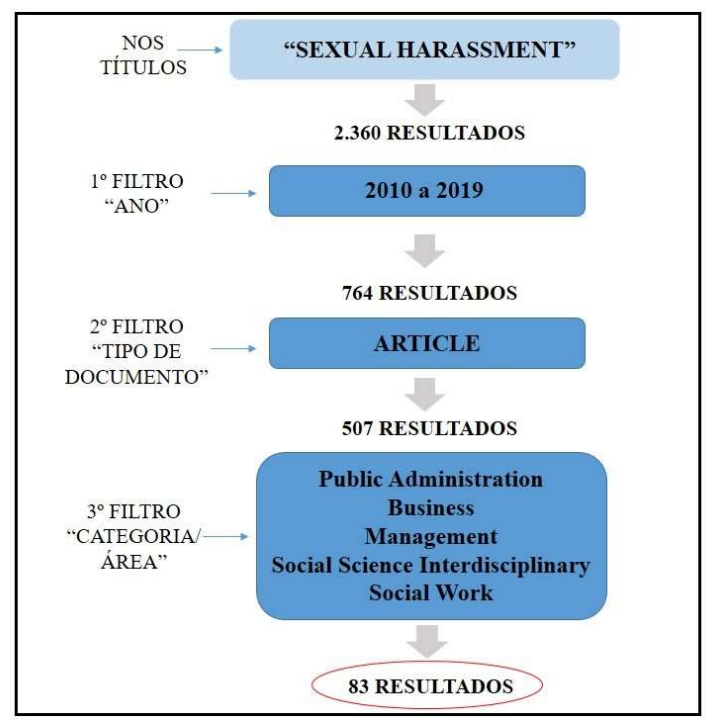

\footnotetext{
${ }^{5}$ A ANPAD (Associação Nacional de Pós-Graduação e Pesquisa em Administração) promove ensino, pesquisa e produção do conhecimento dentro do campo das ciências administrativas, contábeis e afins no Brasil.
} 


\section{RESULTADOS E DISCUSSÃO}

A seguir, são apresentados os resultados do estudo bibliométrico referente às produções encontradas sobre assédio sexual nas bases da ANPAD e Web of Science. Na primeira base, foram identificados título, autores e universidades, ano de publicação e breve resumo das pesquisas. Na segunda base, foi investigado o perfil geral das publicações (áreas, ano, autores, idiomas e países), seguido de uma análise mais aprofundada dos artigos mais citados.

\section{PRODUÇÃO ENCONTRADA NA BASE DA ANPAD}

A partir da busca realizada na base de dados da ANPAD através do termo "assédio sexual", foram localizados apenas 3 (três) artigos sobre a temática. A Tabela 1 traz informações como título, autores e suas universidades, além do ano da publicação dos artigos. Em seguida, é exposto um breve resumo sobre cada uma das pesquisas.

Tabela 1 - Artigos encontrados na base ANPAD

\begin{tabular}{|c|c|c|c|}
\hline Título & Autores & Universidade & Ano \\
\hline \multirow{2}{*}{$\begin{array}{l}\text { "O Assédio Sexual, Ele Deixa } \\
\text { Cheiro, Ele Deixa Cor, Ele Deixa } \\
\text { Nojo": O Estabelecimento da } \\
\text { Precariedade Subjetiva Por Meio } \\
\text { Do Assédio Sexual }\end{array}$} & Moura, R. G. & \multirow{2}{*}{$\begin{array}{l}\text { Universidade do Grande Rio } \\
\text { (UNIGRANRIO) }\end{array}$} & \multirow{2}{*}{2019} \\
\hline & Campos, C. M. A. & & \\
\hline \multirow{2}{*}{$\begin{array}{l}\text { Debatendo o dito pelo não dito: } \\
\text { a problematização do assédio } \\
\text { sexual nas organizações }\end{array}$} & Oleto, A. F. & Fundação Getúlio Vargas & \multirow{2}{*}{2019} \\
\hline & Palhares, J. V. & $\begin{array}{l}\text { Universidade Federal de } \\
\text { Minas Gerais }\end{array}$ & \\
\hline \multirow{2}{*}{$\begin{array}{l}\text { Assédio Sexual no Contexto } \\
\text { Acadêmico da Administração: } \\
\text { não dito por que não } \\
\text { vivenciado? }\end{array}$} & Teixeira, J. C. & $\begin{array}{l}\text { Universidade Federal de São } \\
\text { João del-Rei }\end{array}$ & \multirow{2}{*}{2017} \\
\hline & Rampazo, A. V. & $\begin{array}{l}\text { Universidade Estadual de } \\
\text { Londrina }\end{array}$ & \\
\hline
\end{tabular}

Moura e Campos (2019) buscaram verificar como o assédio sexual se manifesta em locais específicos (ambiente de trabalho) e/ou decorrentes desses locais ao qual diversos sujeitos fixam suas formas de vida. O objetivo final consistiu em investigar se o assédio sexual é umas das formas de se estabelecer um contexto de precariedade subjetiva do trabalho feminino. A metodologia utilizada foi a realização de onze entrevistas em profundidade com mulheres residentes no estado do Rio de Janeiro, e que atuavam em diversos tipos de organizações, seguida da Análise do Discurso Francesa pela ótica de Foucault.

Oleto e Palhares (2019) buscaram, através de uma pesquisa bibliográfica, analisar a literatura sobre assédio sexual nas relações de trabalho, levantando as principais abordagens e 
perspectivas teóricas que podem ser apontadas para as pesquisas sobre o tema, e assinalando fatores relevantes que o contextualizam. Ademais, os autores buscaram fornecer um panorama geral das características que cercam o assédio sexual, tais como as motivações para sua ocorrência, papel das vítimas e agressores, consequências, relação das organizações com esse tipo de violência, entre outros tópicos.

Já Teixeira e Rampazo (2017) objetivaram, eu sua pesquisa qualitativa, analisar os elementos discursivos originados a partir da temática de assédio sexual no âmbito específico da academia brasileira em Administração. Para isso, utilizaram as narrativas de duas mulheres docentes e pesquisadoras, com trajetória acadêmica no campo de estudos da Administração, que foram analisadas por meio da abordagem teórico-metodológica da Análise do Discurso de Linha Francesa.

A partir da busca realizada na base de dados da Associação Nacional de Pós-Graduação e Pesquisa em Administração pode-se perceber que o tema assédio sexual não vem recebendo grande atenção por parte dos pesquisadores brasileiros da área da Administração, visto que só foram localizados 3 artigos relacionados ao tema na referida base de dados. Para Santos (2018), de um modo geral, a falta de estudos sobre assédio sexual no Brasil pode se dar devido ao fato de que o país é fortemente marcado pela cultura machista e patriarcal.

A seguir, são expostos os resultados da busca no que se refere à produção sobre o assédio sexual localizada na base Web of Science.

PRODUÇÃO ENCONTRADA NA WEB OF SCIENCE

\section{PERFIL GERAL DAS PUBLICAÇÕES}

A pesquisa bibliométrica realizada na base de dados Web of Science através do termo "sexual harassment" nos títulos dos documentos localizou 2.360 registros na base. Após fazer o refinamento especificamente para o período de 2010 a 2019, o número foi reduzido para 764. Em seguida, ao refinar os resultados por tipo de documento, selecionando apenas artigos, foram obtidos 507 resultados, em diversas áreas, como mostra a Figura 2, que apresenta as dez áreas com maior número de produções sobre a temática. Assim, o gráfico apresenta o percentual de cada área sobre o total de 507 artigos encontrados. Como bem colocam Schuster, Battistella e Dias (2012), muitos artigos compreendem mais de uma área de relação, assim, o gráfico é meramente representativo, elucidando as áreas que mais se sobressaem nas pesquisas sobre o tema. 
Figura 2 - Percentual das relações da temática por área.

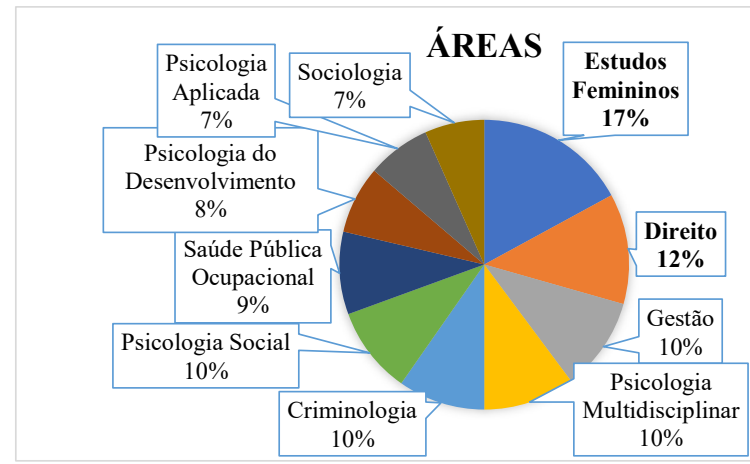

Como pode ser visto no gráfico, as duas áreas (categorias do Web of Science) que dominam as produções sobre a temática foco são as áreas de Estudos Femininos (17\%) e Direito (12\%). O gráfico mostra que o assédio sexual é uma temática que pode ser diferentemente trabalhada por várias áreas, corroborando com o que colocam Fonseca et al. (2018, p. 33), que afirmam que "o assédio sexual no trabalho apresenta-se como temática de interesse de diversas áreas do conhecimento e vem sendo discutido mundialmente a partir de diferentes enfoques". Contudo, percebe-se que não é foco da área de administração, uma vez que, das áreas correlatas à administração posteriormente utilizadas como refinamento da busca, só aparece entre as 10 que mais se destacam a "Gestão", com 10\% das publicações.

Após o refinamento anteriormente citado no método, no que se refere à escolha das áreas somente relacionadas à administração, o número de artigos foi reduzido de 507 para 83, reforçando que a grande massa de publicações sobre assédio sexual não é proveniente de áreas correlatas à administração. A distribuição dos 83 artigos por ano pode ser visualizada na Figura 3.

Figura 3 - Número de artigos publicados por ano.

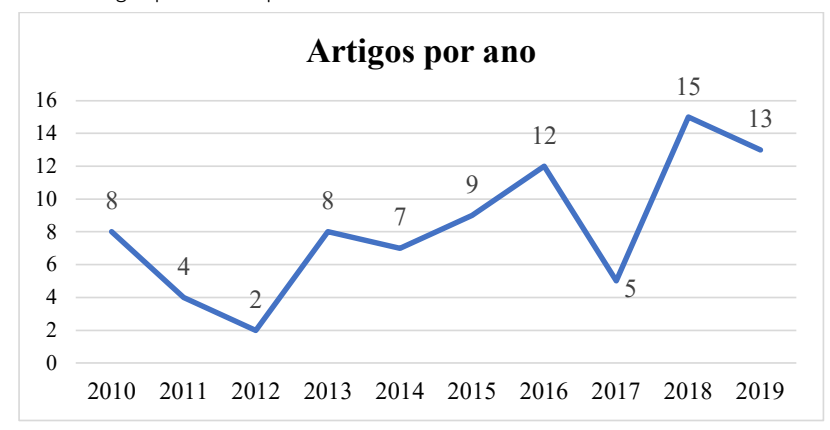


A partir da análise do gráfico, pode ser percebido que a produção mundial sobre assédio sexual oscila muito no que se refere ao número de publicações. Não se pode dizer que o crescimento vem se mantendo constante, uma vez que, nos últimos 4 anos, o número de artigos se manteve variado, sendo 12 em 2016, 5 em 2017, 15 em 2018 e 13 em 2019. Ainda assim, se comparado com os dados do início da década, pode-se dizer que nos últimos anos (exceto 2017), a temática recebeu mais atenção por parte dos pesquisadores.

Quanto aos países de origem dos artigos, quem domina a produção mundial sobre assédio sexual nas áreas correlatas à administração são os Estados Unidos da América, representando $51,8 \%$ do total de tais publicações. Na sequência do ranking estão a Austrália (10,8\%) e Canadá (6\%). Outros países, como Inglaterra, China e Índia aparecem na sequência, porém não alcançaram nem $5 \%$ das publicações. O Brasil não aparece na lista. No que se refere ao idioma, 81 artigos (correspondendo a 97,59\%) são em inglês, e apenas 2 (2,41\%) em francês.

Outro dado relevante sobre o estudo do tema se refere aos autores com maior número de publicações. Destacam-se os pesquisadores Kwan, Madera e Perry, todos com 3 publicações. Nota-se que, mesmo sendo estes os autores com maior número de artigos sobre assédio sexual, o número não é expressivo. Kwan é pesquisador Chinês e acumula 980 citações no Web of Science. Madera e Perry são pesquisadores dos Estados Unidos, sendo que aquele foi citado na base 609 vezes, enquanto Perry teve 498 citações. Os dados mostram que, apesar de ter poucos artigos, estes autores são importantes para a área, uma vez que são muito citados na base.

\section{ANÁLISE DE DADOS}

Após análise quantitativa e representação dos dados, foram escolhidos os 10 artigos mais citados (foram ordenados por número de citações) para breve análise. A Tabela 2 a seguir traz uma síntese das pesquisas, apresentando os títulos, autores, periódico de publicação com fator de impacto, e ano, além do número de vezes que o artigo foi citado na base. Está apresentado em ordem decrescente no que se refere ao número de citações.

Tabela 2 - Lista dos dez artigos sobre assédio sexual mais citados na Web of Science

\begin{tabular}{l|l|l|l|l}
\hline Título & Autores & Periódico & Ano & Citações \\
\hline $\begin{array}{l}\text { Comparing Victim Attributions } \\
\text { and Outcomes for Workplace }\end{array}$ & $\begin{array}{l}\text { Hershcovis, M. S.; Barling, } \\
\text { Aggression and Sexual }\end{array}$ & $\begin{array}{l}\text { Journal of Applied } \\
\text { Psychology (Fator de } \\
\text { impacto: 249) }\end{array}$ & 2010 & 76 \\
\hline $\begin{array}{l}\text { Sexual harassment among } \\
\text { adolescentes of diferente } \\
\begin{array}{l}\text { sexual orientations and } \\
\text { gender identities }\end{array}\end{array}$ & $\begin{array}{l}\text { Mitchell, K. J.; Ybarra, M. } \\
\text { L.; Korchmaros, J. D. }\end{array}$ & $\begin{array}{l}\text { Child Abuse \& Neglect } \\
\text { (Fator de impacto: 129) }\end{array}$ & 2013 & 56 \\
\hline $\begin{array}{l}\text { Sexual Harassment of Women } \\
\text { Working as Room Attendants }\end{array}$ & Kensbock, S.; Bailey, J.; & $\begin{array}{l}\text { Gender Work and } \\
\text { Organization (Fator de }\end{array}$ & 2015 & 30 \\
\hline
\end{tabular}




\begin{tabular}{|c|c|c|c|c|}
\hline within 5-Star Hotels & Jennings, G.; Patiar, A. & impacto: 62) & & \\
\hline $\begin{array}{l}\text { Customer sexual harassment } \\
\text { and frontline employees' } \\
\text { servisse performance in China }\end{array}$ & $\begin{array}{l}\text { Liu, X. Y.; Kwan, H. K.; Chiu, } \\
\text { R. K. }\end{array}$ & $\begin{array}{l}\text { Human Relations (Fator } \\
\text { de impacto: 113) }\end{array}$ & 2013 & 23 \\
\hline $\begin{array}{l}\text { Experiences of Sexual } \\
\text { Harassment and Sexual } \\
\text { Assault in the Military Among } \\
\text { OEF/OIF Veterans: } \\
\text { Implications for Health Care } \\
\text { Providers }\end{array}$ & Bell, M. E.; Reardon, A. & $\begin{array}{l}\text { Social Work in Health } \\
\text { Care (Fator de impacto: } \\
\text { 40) }\end{array}$ & 2011 & 19 \\
\hline $\begin{array}{l}\text { The role of power in sexual } \\
\text { harassment as a } \\
\text { counterproductive behavior } \\
\text { in organizations }\end{array}$ & $\begin{array}{l}\text { Popovich, P. M.; Warren, } \\
\text { M. A. }\end{array}$ & $\begin{array}{l}\text { Human Resource } \\
\text { Management Review } \\
\text { (Fator de impacto: 79) }\end{array}$ & 2010 & 19 \\
\hline $\begin{array}{l}\text { Developing a framework of } \\
\text { effective prevention and } \\
\text { responde strategies in } \\
\text { workplace sexual harassment }\end{array}$ & $\begin{array}{l}\text { McDonald, P.; } \\
\text { Charlesworth, S.; Graham, } \\
\text { T. }\end{array}$ & $\begin{array}{l}\text { Asia Pacific Journal of } \\
\text { Human Resources } \\
\text { (Fator de impacto: 26) }\end{array}$ & 2015 & 17 \\
\hline $\begin{array}{l}\text { Sexual harassment versus } \\
\text { workplace romance: social } \\
\text { media spillover and textual } \\
\text { harassment in the workplace }\end{array}$ & Mainiero, L. A.; Jones, K. J. & $\begin{array}{l}\text { Academy of } \\
\text { Management } \\
\text { Perspectives (Fator de } \\
\text { impacto: } 115 \text { ) }\end{array}$ & 2013 & 17 \\
\hline $\begin{array}{l}\text { Undestanding types, } \\
\text { locations, \& perpetrators of } \\
\text { peer-to-peer sexual } \\
\text { harassment in US middle } \\
\text { schools: A focus on sex, racial } \\
\text { and grade differences }\end{array}$ & $\begin{array}{l}\text { Espelage, D. L.; Hong, J. S.; } \\
\text { Rinehart, S.; Doshi, N. }\end{array}$ & $\begin{array}{l}\text { Children and Youth } \\
\text { Services Review (Fator } \\
\text { de impacto: } 77 \text { ) }\end{array}$ & 2016 & 14 \\
\hline $\begin{array}{l}\text { Retaining employees through } \\
\text { anti-sexual harassment } \\
\text { practices: exploring the } \\
\text { mediating role of } \\
\text { psychological distress and } \\
\text { employee engagement }\end{array}$ & Jiang, K. et al & $\begin{array}{l}\text { Human Resource } \\
\text { Management (Fator de } \\
\text { impacto: 81) }\end{array}$ & 2014 & 14 \\
\hline
\end{tabular}

Hershcovis e Barling (2010) são os autores do artigo mais citado na base de dados, publicado em um periódico de altíssimo impacto. Em sua pesquisa, desenvolveram dois estudos, um investigando características das vítimas e, em outro, as consequências para agressão no local de trabalho e assédio sexual. Com base na teoria da categorização social, argumentam que as vítimas de agressão no local de trabalho podem ter diferentes características em relação às vítimas de assédio sexual. A partir de atribuições diferenciais para 
os dois tipos de maus-tratos, argumentam que as vítimas de agressão no local de trabalho podem apresentar resultados adversos mais fortes do que as vítimas de assédio sexual.

O segundo artigo mais citado compreende a pesquisa de Mitchell, Ybarra e Korchmaros (2013). Os autores buscaram, de forma geral, estudar o assédio sexual entre adolescentes de diferentes orientações sexuais e identidades de gênero. Mais especificamente, examinaram as variações nas taxas de assédio sexual a partir das formas de ocorrência do assédio (local), do seu impacto, e da orientação sexual e identidade de gênero dos jovens.

Kensbock et al (2015) problematizaram o assédio sexual por parte dos hóspedes contra camareiras de um hotel 5 estrelas Australiano. O estudo ilustra as variadas formas, significados e consequências do assédio sexual nesse contexto organizacional específico. Foi revelado que esse tipo de violência contra as camareiras é tratado como algo natural e generalizado. Dentre as condições organizacionais que contribuem para a ocorrência do assédio sexual, foram citados o uniforme "sexualizante", o quarto isolado e a atenção organizacional mínima ao problema. Tal resultado é uma fonte de preocupação considerável, com implicações para a indústria, para instituições de relações de trabalho e para políticas públicas.

O quarto artigo mais citado é de autoria de Liu, Kwan e Chiu (2013). Destaca-se que Kwan acumula 980 citações na base de dados, sendo autor em destaque na temática. A pesquisa dos três autores se refere ao assédio sexual por parte dos clientes contra funcionários da linha de frente Chineses, e o quanto essa prática pode interferir no desempenho destes.

Bell e Reardon (2011) buscaram fornecer uma visão geral dos cuidados clínicos com pessoas que sofreram trauma sexual nas forças armadas, particularmente aqueles que são veteranos de duas operações específicas: OEF (Operation Enduring Freedom) e OIF (Operation Iraqi Freedom). Concentraram-se principalmente no impacto do trauma sexual nas forças armadas, em como as reações dos sobreviventes são moldadas por vários aspectos do contexto militar, além de demonstrarem princípios gerais para ajudar os médicos a trabalhar efetivamente com as vítimas.

A forma como o poder influencia na ocorrência do assédio sexual, e o quanto ambos estão relacionados a comportamentos contraproducentes nas organizações é o foco da pesquisa de Popovich e Warren (2010). Os autores propõem que reconhecer as bases de poder pode ajudar a identificar problemas como assédio sexual, bem como outros incidentes de comportamento contraproducente no trabalho. Além disso, propõem que o assédio sexual e comportamentos contraproducentes relacionados são reflexos de uma cultura de abuso de poder nas organizações.

McDonald, Charlesworth e Graham (2015) buscaram trabalhar com uma estrutura de prevenção e estratégias de resposta ao assédio sexual no local de trabalho, baseados em literaturas pré-existentes sobre prevenção à violência, que conceituam abordagens de 
prevenção e resposta de acordo com a ocorrência. Assim, o artigo sintetiza estratégias identificadas na literatura no que se refere ao assédio sexual e outras injustiças no local de trabalho.

Outro viés da temática foi abordado por Mainiero e Jones (2013), que fizeram uma diferenciação entre o assédio sexual e o romance natural no local de trabalho. Também é dado foco à questão do assédio que pode ser facilitado em uma era ritmo acelerado de uso das mídias sociais, que favorece a ocorrência do assédio textual. Assim, os autores abordam questões de políticas em evolução nas mídias, perspectivas legais e questões de privacidade.

Espelage et al (2016) abordaram tipos de assédio sexual em uma escola de ensino médio dos Estados Unidos e de que modo ocorre, a partir das diferenças de sexo, raça e classe. Os alunos responderam a perguntas abertas sobre o incidente mais perturbador que experimentaram, sobre os autores do assédio e local de ocorrência. Os autores verificaram que, nesse grupo, foi predominante o assédio verbal (e não físico) nos corredores da escola.

Já Jiang et al. (2014), autores do décimo artigo mais citado na base de dados, articularam um modelo de processo levantando a hipótese de que práticas de assédio sexual estão relacionados ao comprometimento afetivo, intenções de permanecer e envolvimento dos funcionários, direta e indiretamente, por meio de estresse psicológico.

A partir da análise, percebe-se que as produções sobre o assédio sexual nas áreas afins da Administração são bastante variadas, abordando diferentes aspectos da temática.

\section{CONSIDERAÇÕES FINAIS}

A bibliometria demonstra que, nacionalmente, na área da Administração, o tema assédio sexual não vem recebendo tanta atenção. Prova disto é que foram localizados somente três trabalhos sobre o tema na base de dados da Associação Nacional de Pós-Graduação e Pesquisa em Administração (ANPAD), que realiza eventos na área. O viés de estudo dos três artigos foi apresentado, sendo que dois deles trabalharam o assédio sexual no local de trabalho, enquanto um trabalhou com a temática no meio acadêmico da administração, evidenciando a lacuna de estudos da temática na área de Administração, especialmente da Administração Pública.

No que se refere à produção encontrada na base Web of Science, há oscilação quanto ao número de publicações por ano no período analisado. O número de artigos se manteve variado, mas, apesar disso, se comparado com os dados do início da década, pode-se dizer que nos últimos anos (exceto 2017), a temática recebeu mais atenção por parte dos pesquisadores.

Como pôde ser evidenciado, grande parte dos artigos sobre assédio sexual na área da administração (e correlatas) é proveniente dos Estados Unidos, representando 51,8\% do total. O idioma predominante nos artigos é o inglês, totalizando $97,59 \%$ destes. No que se refere às 
áreas temáticas que mais publicam sobre assédio sexual, destacam-se a área de Estudos Femininos (17\%) e Direito (12\%). A área de Gestão compreende 10\% das publicações. Os autores que se destacam na produção sobre assédio sexual na base pesquisada são Kwan (China), com 980 citações, Madera (EUA), com 609 e Perry (EUA) com 498 citações. Apesar de terem poucos artigos sobre a temática, estes autores são importantes para a área, uma vez que são muito citados na base em questão.

Foram apresentados os dez artigos sobre assédio sexual mais citados na base de dados, demonstrando as diferentes vertentes que são trabalhadas no que tange à temática que, apesar de não ter crescimento constante, nos últimos anos foi mais estudada do que no início da década analisada (2010-2019). Destaca-se a forte produção de estudo sobre assédio sexual no ambiente de trabalho, tendo em vista que 8 dos 10 artigos da base analisados tinham esse enfoque.

Ao fazer uma análise geral dos artigos da área da administração ou correlatas encontrados na base da ANPAD e da Web of Science, é possível reafirmar a tendência do estudo do assédio sexual vivenciado especificamente no local de trabalho. Do total de 13 trabalhos mencionados, 10 tiveram foco na violência ocorrida no ambiente laboral, mostrando que esta é uma forte tendência de estudo. Ainda assim, dentre os artigos analisados, somente 1 desenvolveu o estudo com base em vivências de organizações públicas: Bell e Reardon (2011), que mencionaram o problema em organizações e servidores militares (Forças Armadas). Portanto, evidencia-se a lacuna de estudos no que se refere ao assédio sexual ocorrido em instituições públicas, especialmente contra servidores públicos civis.

\section{REFERÊNCIAS}

ARAÚJO, Carlos Alberto. Bibliometria: evolução histórica e questões atuais. Em Questão, v. 12, n. 1, p. 11-32, 2006. Disponível em: https://seer.ufrgs.br/EmQuestao/article/view/16/5. Acesso em: 12 jul. 2020.

BELL, Margret E.; REARDON, Annemarie. Experiences of Sexual Harassment and Sexual Assault in the Military Among OEF/OIF Veterans: Implications for Health Care Providers. Social Work in Health Care, v. 50, n. 1, p. 34-50, 2011.

BRASIL, Decreto-Lei n²848, de 7 de dezembro de 1940. Código Penal. Disponível em: <http://www.planalto.gov.br/ccivil_03/decreto-lei/del2848compilado.htm>. Acesso em: 15 jul. 2020.

CONSELHO NACIONAL DO MINISTÉRIO PÚBLICO (CNMP). Assédio Moral e Sexual: previna-se. Brasília, 2016. Disponível em: <http://www.mpf.mp.br/sc/arquivos/cartilha-assedio>. Acesso em: 02 ago. 2020.

DINIZ, Maria Ilidiana. Mulheres como eu, mulheres como as outras: desvelando o assédio 
moral e sexual no âmbito do trabalho das comerciárias no Estado do Rio Grande do Norte. 2014. Tese (Doutorado em Serviço Social - área de Trabalho e Política Social), Universidade do Estado do Rio de Janeiro, Rio de Janeiro, Brasil.

ESPELAGE, Dorothy L.; HONG, Jun Sung; RINEHART, Sarah; DOSHI, Namrata. Understanding types, locations \& perpetrators of peer-to-peer sexual harassment in U.S. middle schools: A focus on sex, racial and grade diferences. Children and Youth Services Review, v. 71, p. 174$183,2016$.

FONSECA, Thaisa da Silva; PORTELA, Ariane Viana Martins; FREIRE, Sandra Elisa de Assis; NEGREIROS, Fauston. Assédio Sexual no Trabalho: uma Revisão Sistemática de Literatura. Ciencias Psicológicas, v. 12, n. 1, p. 25-34, 2018.

HERSHCOVIS, M. Sandy; BARLING, Julian. Comparing victim attributions and outcomes for workplace aggression and sexual harassment. Journal of Applied Psychology, v. 95, n. 5, p. 874-888, 2010.

JIANG, Kaifeng et al. Retaining Employees Through Anti-Sexual Harassment Practices: Exploring the Mediating Role of Psychological Distress and Employee Engagement. Human Resource Management, v. 54, n. 1, p. 1-21, 2014.

JUNIOR, Celso Machado; SOUZA, Maria Tereza Saraiva de.; PARISOTTO, lara Regina dos Santos; PALMISANO, Angelo. As Leis da Bibliometria em Diferentes Bases de Dados Científicos. Revista de Ciências da Administração, v. 18 n. 44, p. 111-123, 2016.

KENSBOCK, Sandra; BAILEY, Janis; JENNINGS, Gayke; PATIAR, Anoop. Sexual Harassment of Women Working as Room Attendants within 5-Star Hotels. Gender, Work \& Organization, v. 22, n.1, p. 36-50, 2015.

LIU, Xiao-Yu; KWAN, Ho Wong; CHIU, Randy K. Customer sexual harassment and frontline employees' servisse performance in China. Human Relations, v. 67, n. 3, p. 333-356, 2013.

MAINIERO, Lisa A.; JONES, Kevin J. Sexual Harassment Versus Workplace Romance: Social Media Spillover and Textual Harassment in the Workplace. Academy of Management Perspectives, v. 27, n. 3, p. 187-203, 2013.

McDONALD, Paula; CHARLESWORTH, Sara; GRAHAM, Tina. Developing a framework of effective prevention and response strategies in workplace sexual harassment. Asia Pacific Journal of Human Resources, v. 53, n. 1, p. 41-58, 2015.

MITCHELL, Kimberly J.; YBARRA, Michele L.; KORCHMAROS, Josephine D. Sexual harassment among adolescentes of different sexual orientations and gender identities. Child Abuse \& Neglect, v. 38, n. 2, p. 280-295, 2013.

MOURA, Renan Gomes; CAMPOS, Claudia Maria Abreu. “O Assédio Sexual, Ele Deixa Cheiro, Ele Deixa Cor, Ele Deixa Nojo": O Estabelecimento Da Precariedade Subjetiva Por Meio Do Assédio Sexual. In: XLIII Encontro da ANPAD - EnANPAD, 2019, São Paulo, Anais... São Paulo. 
OLETO, Alice de F.; PALHARES, José Vitor; PAIVA, Kely César Martins de; GUIMARÃES, Letícia Rocha. Percepções De Tutores Sobre O Assédio Sexual Sofrido Por Jovens Trabalhadores Nas Organizações. Revista Eletrônica de Gestão Organizacional, v. 16, n. 1, p. 43-56, 2018.

OLETO, Alice de Freitas; PALHARES, José Vitor. Debatendo O Dito Pelo Não Dito: A Problematização Do Assédio Sexual Nas Organizações. In: XLIII Encontro da ANPAD EnANPAD, 2019, São Paulo, Anais... São Paulo.

OSTERNE, Maria do Socorro Ferreira. A violência contra a mulher na dimensão cultural da prevalência do masculino. O Público e o Privado, v. 1, n. 18, p. 129-145, 2012.

POPOVICH, Paula M.; WARREN, Michael A. The role of power in sexual harassment as a counterproductive behavior in organizations. Human Resource Management Review, v. 20, n. 1, p. 45-53, 2010.

SANTOS, Marcelo Augusto Finazzi. Trabalho corrompido, dignidade violada: histórias de vida de mulheres assediadas sexualmente em uma organização bancária. 2018. Tese (Doutorado em Administração), Universidade de Brasília, Distrito Federal, Brasil.

SCHUSTER, Marcelo da Silva; BATTISTELLA, Luciana Flores; DIAS, Valeria da Veiga. Análise da evolução do tema justiça organizacional: um estudo bibliométrico. Faces em Revista, v. 4, n. 2, p. 1-17, 2012.

SENADO FEDERAL. 2011. Cartilha sobre assédio moral e sexual. Disponível em: <http://www2.senado.leg.br/bdsf/handle/id/509899>. Acesso em: 13 jul. 2020.

TEIXEIRA, Juliana Cristina; RAMPAZO, Adriana Vinholi. Assédio Sexual no contexto acadêmico da administração: o que os lábios não dizem, o coração não sente? Farol - Revista de Estudos Organizacionais, v. 4, n. 11, p. 1151-1235, 2017.

TEIXEIRA, Juliana Cristina; RAMPAZO, Adriana Vinholi. Assédio Sexual no Contexto Acadêmico da Administração: Não Dito Por Que Não Vivenciado? In: XLI Encontro da ANPAD - EnANPAD, 2017, São Paulo, Anais... São Paulo. 